\title{
Литература
}

1. ГОСТ 15150 - 69. Машины, приборы и другие технические изделия. Исполнения для различных климатических районов. Категории, условия эксплуатации, хранения и транспортирования в части воздействия климатических факторов внешней среды. - М.: Стандартинформ, 2006. - 60 с.

2. ГОСТ 9.602 - 2016. Единая система защиты от коррозии и старения. Сооружения подземные. Общие требования к защите от коррозии. - М.: Стандартинформ, 2016. - 93 с.

3. Зейнетдинов Р.А., Колесникова Т.А. Энтропийный метод анализа тепловых схем в системе теплоэнергоснабжения// Сб. материалов конференции. - Ярославль: ЯГТУ, 2019. - С. 738-742.

4. Каталог стандартных изделий. Шкафные газорегуляторные пункты в исполнении для подземных газопроводов (ШРП-ПГ) с основной и резервной линией редуцирования: без учёта расхода газа, с узлом учёта расхода газа. Издание 2. - Волгоград: Итгаз, 2017. - 48 с.

5. РД 153-39.4-091-01. Инструкция по защите городских подземных трубопроводов от коррозии. - СанктПетербург: Издательство ДЕАН, 2002. - 242 с.

\section{ЭЛЕМЕНТ СИСТЕМЫ МОНИТОРИНГА ТЕРМИЧЕСКИХ УСЛОВИЙ В БИОЦЕНОЗЕ САДА ПРИ РАЗЛИЧНЫХ СИСТЕМАХ СОДЕРЖАНИЯ ПОЧВЫ}

А.Н. Перекопкий, канд. техн. наук, доцент

Контактная информация (e-mail): aperekopskii@mail.ru

\section{А.В. Зыков}

Контактная информация (e-mail): zav35@list.ru

К.И. Егорова, аспирант

Контактная информация (e-mail): unknown_06@list.ru

С.П. Евсеев, аспирант

Контактная информация (e-mail): 1evseevser@ gmail.com

Институт агроинженерных и экологических проблем сельскохозяйственного производства филиал ФГБНУ ФНАЦ ВИМ (г. СПб, РФ)

ВВЕДЕНИЕ. Интеллектуальная система мониторинга и управления «Умный сад» является частью производственной концепции «Умное сельское хозяйство»: интеллектуальной системой подготовки, выполнения и контроля всех технологически операций производства садоводческой продукции. Целью создания «Умного сада» является разработка интеллектуальной технической системы, осуществляющей в автоматическом режиме анализ информации о состоянии агробиоценоза сада, с возможностью принятия управленческих решений и их реализации с помощью роботизированных технических средств $[1,2]$.

Для управления технологиями возделывания садовых культур в ФГБНУ «Федеральный научный агроинженерный центр ВИМ» разработана система интеллектуального управления промышленными технологиями в садоводстве, состоящая из трёх блоков и позволяющая осуществлять контроль за состоянием растения и обеспечивать необходимую агротехнологию ухода [3, 4].

Наши исследования относятся к блоку контроля параметров продукционного процесса, включающего систему контроля жизнедеятельности растений и состояния окружающей среды.

Объектом исследований является почвенная среда в саду в связи с биологическими потребностями активной части корневой системы плодовых культур, в частности яблони.

Роль корня в жизни растений многогранна. Корень - специфический орган поглощения воды и минеральных элементов из почвы. В корнях частично или полностью происходит переработка поступивших ионов, их восстановление и включение в различные органические соединения. Синтетическая деятельность корневой системы, которая особенно активно исследовалась учеными во второй половине прошлого столетия, необходима для обеспечения нормального роста растений $[5,6]$.

Наиболее важными, в функциональном отношении, являются всасывающие корни 
первичного строения, обладающие высокой физиологической активностью. В период самого активного роста эта категория корней составляет до $90 \%$ от всего количества корней растений. Всасывающие корни недолговечны, они отмирают через 15-25-дней после их образования $[7,8]$.

Из факторов среды выделяется роль температуры почвы как показатель жизнедеятельности растения. Диапазон оптимальных температур роста корней, установленный в условиях различных агроклиматических зонах, не имеет значительных различий. Рост активных корней карликовых и полукарликовых подвоев начинается при температуре почвы 5-6 ${ }^{0} \mathrm{C}$; интенсивный рост - при $10-18{ }^{0} \mathrm{C}$; при температуре более 20 градусов - рост корней замедляется; при $26-28{ }^{0} \mathrm{C}$ - рост прекращается. В жаркие дни рост корней продолжается только в глубоких слоях почвы.

Корневая система постоянно находится под влиянием меняющейся температуры почвы. Характер изменений может быть ритмичным (суточные и сезонные ритмы), аритмичным, вызываемый за короткий отрезок времени (изменение температуры воздуха из-за облачности, выпадения осадков). Установлены слабые изменения в скорости роста корней при изменении температуры на $0,3-0,8^{0} \mathrm{C}$; при постепенном повышении температуры (7-9 ночью, 2224 - днём) за 3 часа с 15,4 до $23,6{ }^{0} \mathrm{C}$ скорость роста увеличивается; быстрое повышение температуры почвы с интервалом от минимума до максимума - приводит к гибели корней. Условия начала роста корней находятся в зависимости не только от текущего хода почвенных условий, но и от суммы факторов, складывающихся в период осенних работ $[9,10]$.

Такое физиологически важное свойство корня, как проницаемость плазмы, определяющая скорость всасывания корнями минеральных соединений, так же зависит от температурного режима почвы. Корни первичного строения чувствительны к изменениям водного режима почвы. Нормальное увлажнение почвы для яблони составляет 70-75 \% от предельной полевой влагоемкости. Снижение важности почвы до 65-70 \% резко снижает прирост активных корней.

Гидротермические условия почвы складываются в зависимости от изменений погодных условий. Особое значение для многолетних плодово-ягодных растений, так же как для любой сельскохозяйственной культуры, имеют микроклиматические условия приземного слоя воздуха (ориентировочно до 2 метров от уровня почвы). В приземном слое воздуха вертикальные градиенты всех метеорологических элементов (влажность, температура и др.) оказывают значительное влияние на корни и надземную часть растения $[11,12]$.

Летом в дневные часы температура воздуха в надземном слое возрастает. В ночные часы тепловой баланс поверхностного слоя земли становится отрицательным, так как, вследствие ночного излучения, земля охлаждается. Летом инсоляционный и радиационный типы распределения температуры воздуха с высотой являются основными типами при ясной, безоблачной и тихой погоде. В облачную погоду земная поверхность и прилегающий слой воздуха нагреваются меньше. В ночные часы, при полной облачности, может и не быть температурной инверсии. Тогда температура воздуха над поверхностью земли с высотой не изменяется.

Деятельность корневой системы и надземной части дерева взаимосвязаны и представляют функциональное единство. Роль надземных органов растения, в первую очередь, заключается в непрерывном снабжении корней продуктами фотосинтеза. Основной формой ассимилянтов является сахароза и её полимеры - универсальные источники углеводов и органических соединений для корней. В корневой системе частично или полностью восстановленные ионы включаются в различные органические соединения и транспортируются в надземные органы для использования на построение более сложных метаболитов [13].

Корневая система является доступным объектом воздействия на продукционные процессы дерева в результате изменений почвенных условий под влиянием агротехнических приёмов (системы содержания почвы, удобрений, орошения и др.). Н. Г. Жучков считал [14], что ни одно мероприятие по уходу за садом не следует выполнять без учёта состояния корневой системы и возможной реакции корней на эти агроприемы. 
Цель работы: исследование термических условий почвы в агроценозе сада в связи с биологическими потребностями первичных корней яблони.

ОБЪЕКТ И МЕТОДИКА. Опыт был проведен в яблоневом саду 17-летнего возраста, расположенном на Ленинградской плодоовощной опытной станции ИАЭП-филиал ФГБНУ ФНАЦ ВИМ. Почва сада окультуренная, перегнойно-карбонатная супесчано-пылеватая на карбонатном суглинке с мощностью гумусового горизонта 0,3-0,31 м. Объёмный вес почвы в слое $0-0,2 \mathrm{M}-1410 \mathrm{\kappa} г \mathrm{~m}^{3}$, в слое $0,2-0,4 \mathrm{~m}-1410 \mathrm{\kappa} / \mathrm{m}^{3}$, в слое $0,4-0,6 \mathrm{м}-1540 \mathrm{\kappa} / \mathrm{m}^{3}$.

Содержание почвы в саду осуществляли по 2-м системам: постоянное задернённые почвы многолетними злаковыми травами в форме дерново-перегнойной системы и постоянное рыхление почвы - чёрный пар. Возраст дернины в варианте задернения почвы составлял 3-4 года. Вариант - год, характеризовавшийся показателями метеорологических элементов, близкими к среднемноголетним. Сумма осадков за год составляла 662 мм (за вегетационный период - 344 мм), ГТК=1,8. Теплая погода в феврале и марте чередовалась с холодной - в конце марта и апреле. В короткий период засухи наблюдался дефицит влажности почвы.

Температура почвы определялась прибором ЭТП. Датчики прибора были установлены по линии в ряд на расстоянии 1,5 метра от штамба деревьев в почве на глубине: 0,1, 0,2, 0,4 и 0,6 метра. Определение температуры велось дистанционно. Для этого провода от датчиков помещались в деревянный контейнер, врытый в верхний слой почвы на расстоянии 1,5 метра от места размещения датчиков. Поверхность почвы в месте размещения датчиков искусственно защищалась от утаптывания.

Период исследований происходил в тихую и солнечную погоду для устранения метеорологических изменений. Определение температуры и относительной влажности воздуха на высоте 0,1 метр от уровня почвы были проведены 20 и 21 июля. Суточные определения температуры задернённой и паровой почвы - на глубине почвы 0,1, 0,2, 0,4 и 0,6 метра проведены 7-8 сентября 2020 года.

Контрольное измерение температуры почвы определялось три раза в сутки (9-00, 1200,15-00) в течение 6 месяцев вегетационного периода. В варианте 70 дней определение сопровождалось измерением температуры и влажности воздуха на поверхности почвы на высоте 0,1 метра аспирационным психрометром. В зимнее время температура почвы определялась эпизодически.

РЕЗУЛЬТАТЫ ИССЛЕДОВАНИЯ. Данные, полученные в конкретных условиях окружающей среды и базового варианта содержания почвы в саду (чёрный пар), позволяют характеризовать температурный режим почвы как благополучный для роста корней яблони. Температура в слое почвы 0-0,6 м (к моменту максимального прогрева в 15 часов) в начале вегетационного периода, середина апреля - середина мая, складывалась в пределах 5,5$10,2{ }^{0} \mathrm{C}$; в период с середины мая по третью декаду сентября - 10,9-18,2 ${ }^{\circ} \mathrm{C}$.

В целом результаты исследований фрагментально отражают основные закономерности теплового баланса почвы. В условиях содержания почвы в различных агротехнических режимах (задернение и чёрный пар) проявились особенности в формировании теплообеспеченности каждого из них. Растительный покров почвы является экраном, который уменьшает приход солнечной энергии к поверхности почвы, но и затрудняет расход тепла на излучение. Эти процессы происходят постоянно в течение суток, оказывая большое влияние на тепловой режим почвы и определяя особенности температурного режима задерненной и паровой почвы.

Под влиянием погодных условий происходит постоянное изменение температуры почвы и воздуха на поверхности почвы. Характер динамики температурных изменений наиболее полно отражают данные разницы температур двух смежных дней, т.е. величина изменений температуры в течение суток, представленные на рис. 1. Среднесуточная температура 7 сентября 2020 года составляла $14,8^{0} \mathrm{C}$.

В результате обработки полученных данных установлено что наибольшая амплитуда колебаний температуры паровой почвы в суточном интервале происходит в поверхностном слое почвы (глубина 0,1 м). Резкое снижение температуры почвы вызывает солнечная ветре- 
ная погода. Длительное воздействие таких условий вызывает снижение температуры почвы и на глубине 0,6 м. В пасмурную, дождливую, облачную погоду амплитуда колебаний суточных изменений температуры почвы приближается к показателям задернённой почвы. В задернённой почве динамика суточных изменений температуры почвы более сглажена по сравнению с суточными изменениями температуры в паровой почве. При смене солнечной погоды пасмурной дождливой погодой температура поверхностного слоя почвы снижается меньше, чем в таких же условиях в паровой почве.

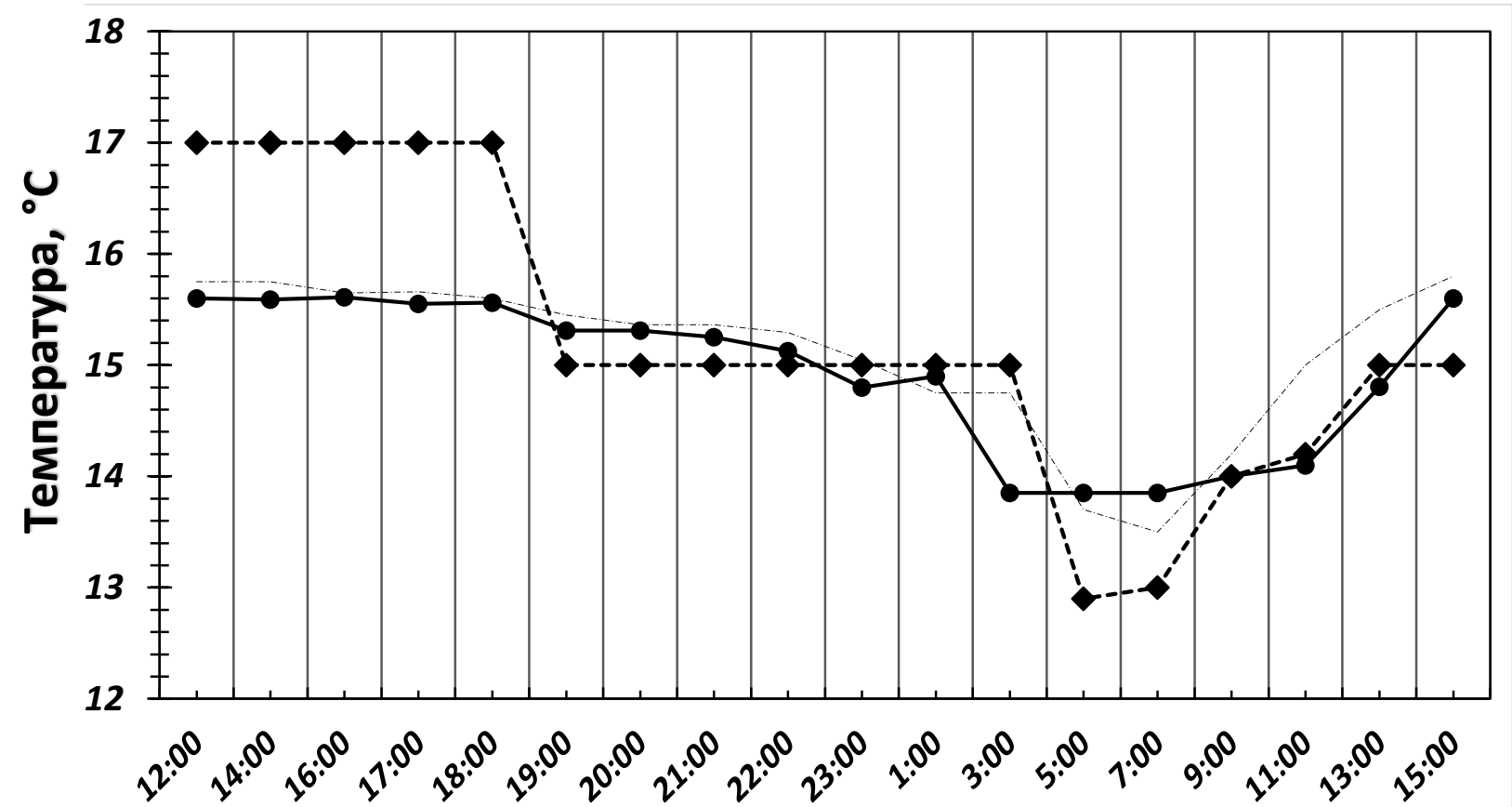

Время 7 сентября - 8 сентября 2020 года, час

—— Среднее заначение температуры задернения почвы на глубине от 0,1 до 0,6 метра

Среднее значение температуры паровой почвы на глубине от 0,1 до 0,6 метра

--॰-- Температура окр.воздуха, ${ }^{\circ} \mathrm{C}$

Рис. 1. Среднесуточное изменение температуры задернелого и парового опытного участка сада

Особенности суточных изменений температуры почвы на разных глубинах связаны с распределением температуры почвы по вертикали в разное время суток. Метеорологические условия начала сентября характеризовались тёплой устойчивой погодой, когда температура воздуха к 15 часам достигала $16-23{ }^{\circ} \mathrm{C}$, а ночью - опускалась до $10{ }^{\circ} \mathrm{C}$. При таком тепловом режиме активизируется рост всасывающих корней.

Суточное изменение температуры почвы до глубины 0,4 метра - динамично. Все суточные изменения в этом слое почвы происходят в довольно узких температурных пределах; в паровой почве в интервале $-15,8-15,45^{\circ} \mathrm{C}$, в задернённой $-15,6-14,7^{\circ} \mathrm{C}$.

Сезонное и суточное изменение интенсивности солнечной радиации и выпадение осадков вызывают колебания температуры верхних слоев почвы. Задернелые участки почвы не подвержены резкому насыщению влагой с последующей быстрой отдачей (испарением). В ходе наблюдений выявлено, что при увеличении влажности почвы, увеличивается теплопроводность. При изменении влажности с 0,13 до 25-30 \% приводит к росту теплопроводности в 5 раз.

ВЫВОДЫ. Показатели изменения температуры, влажности почвы и воздуха, напрямую влияют на жизненный цикл растении.

Получаемые данные будут использованы для разработки информационной системы мониторинга состояния биообъекта и получения общих данных об изменениях состояния сада и окружающей среды. 
Анализ результатов работы позволил конкретизировать дальнейшее определение параметров значимого процесса в связи с деятельностью корней в условиях почвенной среды и влияния внешних условий сада.

Концепция «Умное сельское хозяйство», и в частности «Умный сад», основана на использовании различных инновационных решений. Элементы мониторинга термических условий почвы в биоценозе сада являются этапами перехода к цифровому сельскому хозяйству. Разработки в этом направлении позволят роботизировать сельскохозяйственную отрасль, повысить урожайность и снизить затраты производства.

\section{Литература}

1. Кирюшин В.И. Цифровое земледелие// Вестник российской сельскохозяйственной науки, № 5, 2018. - С. 49.

2. Измайлов А.Ю., Смирнов И.Г., Хорт Д.О. Цифровые агротехнологии в системе «Умный сад»// Садоводство и виноградарство, 2018. - № 6. - С. 33-39.

3. Измайлов А.Ю., Смирнов И.Г., Хорт Д.О. Информационно-аналитическое обеспечение машинных технологий производства посадочного материала плодовых и ягодных культур// Садоводство и виноградарство, 2018. - № 2. - С. 61-67.

4. Хорт Д.О., Смирнов И. Г., Филиппов Р.А., Вершинин Р.В. Обоснование параметров системы автоматического орошения «Умного сада»// Инновации в сельском хозяйстве, 2018. - № 3 (28). - С. 123-127.

5. Рязанцев П.А., Кабонен А.В., Родионов А.И. Определение архитектоники корневой системы деревьев методом георадиолокации// Вестник Томского государственного университета. Биология, 2020. - № 51. - С. 179-204.

6. Кузин А.И., Трунов Ю.В., Соловьев А.В. Оптимизация азотного питания яблони (malus domestica borkh) при фертигации и внесении бактериальных удобрений// Сельскохозяйственная биология, 2018. - Т. 53. - № 5. - C. $1013-1024$.

7. Михайлова О.А. Особенности онтогенеза Crambe Maritima L. в условиях Ex Situ// Ученые записки Крымского федерального университета имени В.И. Вернадского. Биология. Химия, 2015. - Т. 1 (67). - № 2. - С. $105-115$.

8. Усольцев В.А. В подвалах биосферы: что мы знаем о первичной продукции корней деревьев// Экопотенциал, 2018. - № 4 (24). - С. 25-79.

9. Рязанцев П.А. Определение архитектоники корневой системы деревьев методом георадиолокации/ П.А. Рязанцев, А.В. Кабонен, А.И. Родионов// Вестник Томского государственного университета. Биология, 2020. - № 51. - С. 179-204.

10. Перекопский А.Н., Зыков А.В., Егорова К.И. Оценка сортов смородины черной на пригодность в комбайновой уборке// Аграрный научный журнал, 2021. - № 7. - С. 35-39.

11. Ненько Н.И., Киселева Г.К., Шестакова В.В. [и др.] Адаптационная устойчивость яблони к гидротермическим условиям зимнего и летнего периодов// Плодоводство и виноградарство юга России, 2017. - № 45(3). - C. 33-48. [Электронный ресурс]. - Режим доступа URL: http://journal.kubansad.ru/pdf/15/05/17. (Дата обращения 26.07.2021 г.).

12. Васильев С.М., Штанько А.С., Удовидченко Я.Е. Методика прогнозирования параметров корневых систем яблоневых растений// Аграрный научный журнал, 2020. - № 8. - С. 76-82.

13. Краюшкина Н.С. Барыльник К.Г. Рециркуляция элементов минерального питания в условиях постоянного задернения почвы в плодовом саду// Региональная экология, 2015. - №5 (40). - С. 39-42.

14. Жучков Н.Г. Агробиологические основы плодоводства. - Ленинград: Лениздат, 1962. - 119 с. 